\title{
Study on Education Mode of "Children of Migrant Workers" under the Background of Educational Informationization
}

\author{
Wei Xu \\ School of Music \\ Heihe University \\ Heihe, China
}

\begin{abstract}
The migrant worker is a group emerges rapidly after the reform and opening up of our country. And one of the important issues they care about is their children's education problem. The settlement of migrant children's education problem is related to whether or not the quality of Chinese farmers can be improved. And the quality enhancement is related to the increase of farmers' income as well as the agricultural and rural economic development, at the same time, it is also related to the process of building a harmonious society in China. But the education development of the children of migrant workers has been restricted due to the imperfection of government policy, the relatively poor and backward rural areas, and the level of education of migrant workers themselves is relatively low. Therefore, we should take active measures to help children migrant worker to realize education equality, with the specific measures including: to speed up rural development; set up special schools for children of migrant works by government; government should play a guiding role; protect the migrant workers' rights and interests and other measures to achieve the goal of compulsory education and basic education, and to realize the sustainable development of China's economy and society and social stability.
\end{abstract}

Keywords-children of migrant workers; education; development

\section{INTRODUCTION}

In 2010, China issued the National Medium and Long-term Education Reform and Development Outline, which has proposed that "the fundamental measure is to allocate education resources rationally, incline to the rural areas, remote poverty regions and minority areas, and speed up to narrow the gap in education." However, because the overall education resources allocation in city is better than that of rural areas in China, and such situation is hard to be changed largely within a short period. The textbook version adopted by part of the rural schools is different from that of the urban schools in addition to the rural schools cannot be equipped with the completed and necessary teaching equipment, which will bring difficulties for the children of migrant workers in terms of learning, making them unable to keep up with the teaching progress when they come to the urban school to study. However, the developed areas have the absolute education resources and the less developed areas have the contrary circumstances. Migrant works tend to work in the developed areas, hoping to have a better development, not only in terms of their income, but also in terms of better education for their children. Most of the children of migrant works are in the sage of receiving compulsory education and the physical and mental development stage, and their understanding toward society and city is changing subtly, yet such change can be positive or negative. As for this aspect, the school education is particularly important for the health growth of children of migrant workers.

\section{PROBLEMS EXIST IN CURRENT EDUCATION OF CHILDREN OF MIGRANT WORKERS}

At present, there are two approaches for the education of children of migrant workers in city, one is to attend public schools, and the other is to attend private schools or schools for peasant workers' children. If they attend public school, on the one hand, they will face great economic pressure, and on the other hand, the psychological discrimination is more intolerable than the unfair material conditions. Sometimes, this idea cannot be changed. In some private schools, although the charges is relatively low and admission procedure is relatively simple with less psychological discrimination, there are great differences between these schools and public schools in terms of funds, management and teachers, which will affect students' learning effect directly. Especially in recent years, more and more urban schools implement the new basic reform, new curriculum reform and change the traditional teaching behavior, making the difference between urban and rural school more and more obvious. The teaching methods and means in part of the rural schools are simple, which is the teacher-centered classroom, and the teaching behavior between teachers and students is reflected as controlling and obedience. The teaching methods and means in most of the urban schools are flexible and diversified, and students' enthusiasm to participate in classroom teaching is higher, reflecting as knowledge-centered teaching pattern between teachers and students, and the teaching behavior is mainly mutual consultation, which is different from that of the rural schools. As for the children of migrant workers, the preconceived traditional rural teaching behavior has been engraved in their thinking, and when they entered the urban school, they will at loose with great psychological pressure facing the new 
classroom interaction between teachers and students as well as the teaching behavior. Many children of migrant workers will sever themselves from the classroom to be the grey group of classroom teaching, resulting in unsuccessful academic achievements, or the destroyer of classroom teaching, affecting the normal classroom teaching.

Classroom behavior standard is the value system to regulate the behavior of students in classroom, which restrains and controls students' classroom behavior to a large extent, and control students' individual will within the social normative system. The classroom standard consciousness that has been formed in the depth of students' heart will often influence and restrict their classroom behavior directly, and the degree of students' identification and obedience of classroom standards will influence their behavior in classroom. Most of the children of migrant workers have received rural school education more or less prior to their entering into urban schools. So they are familiar with the standards of rural schools, and the classroom standards with rich rural school cultural characteristics have been formed in their mind. After their entering into urban schools, they will feel being constrained with repression as the new classroom standards are different from that of rural schools, the learning environment is changed, there is difference between classroom spirit and connotation, thus affect their observance to the classroom standards of urban schools. And they will often disrupt the classroom teaching with misbehavior, challenging the school teaching management seriously.

\section{REFLECTION ON EDUCATION MODE OF CHILDREN OF MIGRANT WORKERS AND ADJUSTMENT}

At present, China is in the social transition period. The current education for children of migrant workers have reflected many problems, but in essence, it has revealed the contradictions and conflicts between current education policy for children of migrant workers and social transformation. In the final analysis, many shortcomings still exist in current education policy for children of migrant workers and the education system, which cannot keep up with the requirements of rapid social transformation. Of course, since the middle of 1990s, the education policy for China's migrant children has been adjusted a lot, some urgent problems have been solved preliminarily. But obviously, from the current situation of migrant children's education, this problem hasn't been solved really. Migrant children education problem is an inevitable result of China's rigid and conservative traditional social management system's failure to adapt to the continuous urbanization. It involves a wide range, and actually it has gone far beyond the category of compulsory education and the pure education category, which is related to a series of social, political, and economic problems of household registration management, financial system, tax policy, social security and civil rights. The construction of education policy for children of migrant workers in future must be conducted based on these complex and deep level problems.

\section{A. Change Education Mode by Using the "Compulsory Education Voucher" System}

The unified budget of compulsory education made by the central government just generally solved the source of educational funds for the school-age children in China. But how to allocate this budget fairly and reasonably still need to be discussed. The allocation of central budget must eventually be carried out by the local government with the allocation proportion to be determined by the quantity measurement of all school-age children in various areas (including floating population). However, the local government is difficult to accurately grasp the size of inflow and outflow school-age children in the region due to the unstable and unpredictable characteristics of population mobility. The traditional resource allocation based on household registration is proved to be infeasible. The children of migrant workers will be "marginalized" as usual, becoming the object "without management", and they cannot enjoy the normal treatment. In this case, some of the government with outflow population actively conduct collaboration with the government with inflow population, and establish the "tracing school" by the outflow government in the local area where the outflow population are concentrated, build the schools for children of migrant workers with joint contribution. This method also has great limitations because the migrants are quite scattered, which can only meet the needs of a relatively small part of the outflow school-age children. Even in the city where the native outflow population is concentrated, migrants are scattered in different parts of the city, and the establishment of "tracking school" still can't realize migrant children's nearby enrollment, while the tracking school cannot be established everywhere due the limitation of cost effect. Now, the trial "compulsory education voucher system" may be an effective method to solve this problem. American Milton Friedman, the Nobel Economics Prize winner, has first put forward the theory of "education voucher". The education voucher system proposed by Friedman refers to that government give the public funds used for education directly to the students or their parents in the form of will be used in the education of in the form of voucher, rather than to schools; students can choose school freely and pay tuition and related fees using the education vouchers; schools collect cash inflow with the value equal to the vouchers from the government. So that students can attend any school that is recognized by the government by virtue of education vouchers. At the same time, the competition between schools will be increased due to the power of initiative mastered by the students, so as to improve the overall quality of school education. Under the background that the current household registration system hasn't been reformed thoroughly, the government can consider to learn from the experience of western countries, carry out a trial "compulsory education voucher" system facing migrants, to guarantee the right of equality compulsory education for children of migrant workers.

\section{B. Enrich Education Modes by Using Public Education Resources}

The education policy for children of migrant workers shall take fairness as the primary value goal, to eliminate social exclusion and promote social inclusion. The education for 
children of migrant workers shall be involved in the system from outside system in all directions, enabling it to integrate to the education order of the mainstream schools in the society. The priority of main resolution channel shall be given to public schools with private education as complementary, at the same time, adjust the existing education resources distribution appropriately, allocate reasonably the existing state-owned public education resources, to maximize the use of existing resources. The government with inflow population shall relocate the education resources according to the scale of source of students in existing primary and secondary schools. In fact, under the circumstances that large amount of children of migrant workers cannot attend to school, some of the primary and secondary schools are revoked due to the decreasing local student source resulted by the changes in family structure. The government with inflow population shall transfer the spare resources effectively to strengthen the public schools in the area where migrants are concentrated, in order to improve the ability of these schools to serve the schooling for children of migrant workers, and the education quality for children of migrant workers, or transform to the schools that mainly recruit migrant children, to better meet migrant children's demand for education. For example, in the citysuburban area with concentrated floating population, the school-running ability as well as the ability to recruit students shall be improved, or new schools shall be established, to solve the problem of migrant children having difficulty in entering into schools in local area.

\section{Accelerate the Informationization Construction Promotion Mode of Education Management Means}

In order to effectively strengthen the dynamic supervision migrant children's education and provide convenient education conditions, it is necessary to accelerate the construction of informatization of education management. For instance, some scholars put forward to intensify the regulation of electronic registration management system and establish a national unified electronic registration management system, to realize the national electronic registration management system networking, thus to serve the migrant workers' children for their enrollment, school transferring and entering a higher school and establish a nationwide electronic registration management system. At present, many cities have established an electronic registration management system which is powerful but difficult to operate. Such electronic registration management system is invested by the government and mainly developed by enterprise, takings school management as the center and the students as service object. It not only has the functions of statistics, querying and browsing the primary and secondary school registration information, but also has the functions of basic information management, student information management, school registration management, study management, query and statistics, etc. This kind of electronic management system has not only greatly reduced the management cost, but can master each student's entering, attendance, school transferring, and school dropout through the electronic tracking system, to ensure every child can go to school, and achieve the education concept of serving each student.
Children of migrant workers cannot adapt to the system culture of rural schools due to the specificity of their learning, life and education background. Urban schools shall be optimized from form to content of the system, and pay attention to the organic combination of rigid constraints and humanistic care, especially the perfection of evaluation system. The establishment of school system culture should reflect the strategy for student management and the flexibility evaluation mechanism. First, the evaluation on students shall be transferred from single to multiple. Migrant children and urban students have their own special points in academic performance and practice ability. The education on students shall not only focus on academic performance, what is more important is the evaluation on students' development potential. Second, as for the student management system, peopleoriented idea shall be highlighted to encourage students to follow the standard behavior as recognized by the public. Urban schools shall consider the different characteristics of urban and rural students while they are formulating rules and regulations and the code of conduct, to work out the behavioral norms suitable for the demand of different student groups. Third, establish reasonable and fair system of class. The class is the main carrier of students' life and learning, and classroom management system has more profound influence on students than the school rules and regulations. Class system itself is a kind of invisible course, which shall enable all students to feel the reasonable and fair education. Class system should try to avoid the system that urban students can enjoy but the rural students cannot.

Urban cultural integration of children of migrant workers shall be improved and perfected from many aspects such as social system, and school culture integration is only one kind of beneficial attempts. School should respect the cultural differences to discover the common ground between urban and rural students, try to avoid or eliminate the psychological differences between urban students and migrant children. Create a good atmosphere of culture education, build a school education pattern with multicultural integration, and accelerate the school cultural integration, to finally achieve the goal of migrant children's integration into society.

\section{REFERENCES}

[1] Huang Xiaona. Rural Left-behind Children-Vulnerable Group Not to be Ignored [J]. Medicine and Society, 2005(2).

[2] Zhou Yongping. Analysis of Education Situation of School-aged Migrant Children in Beijing [J]. Journal of China Youth University for Political Sciences, 1998(2).

[3] Zhang Binxian. Current Situation of Education Research on Migrant Children and the Trend [J]. Tsinghua Journal of Education,2001(4).

[4] Chen Xuzhong. Exploration of Healthy Personality Education for "Leftbehind Middle School Students" [J]. Journal of Shenyang College of Education, 2005(1). 